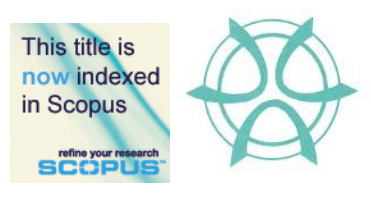

PLANNING MALAYSIA:

Journal of the Malaysian Institute of Planners

VOLUME 15 ISSUE 1 (2017), Page 245 - 254

\title{
THE IMPACT OF INTANGIBLE FACTORS IN SHAPING THE IDENTITY OF ANCIENT CITIES AND ARCHITECTURE OF CHINA
}

\author{
Tamara Kelly ${ }^{1}$ \\ ${ }^{1}$ Department of Architecture and Design \\ ABU DHABI UNIVERSITY, UNITED ARAB EMIRATES
}

\begin{abstract}
China is an immense nation and highest population on earth with incredible civilization, it kept up its character over millenniums in spite of its different ethnic gatherings and distinctive geographical conditions. The Ancient Chinese architecture and urban planning are fundamental units of the world architecture and well known of their particular character. In addition, they were an extraordinary wellspring of motivation for some neighbouring nations. Several factors were behind the momentous Chinese architecture and urban planning, and among those was the emperor guidance who unified the government and encouraged regularity in many aspect in Chinese architecture including city planning. The aim of this paper is to examine the impact of nonphysical factors such as Chinese culture and beliefs in shaping the distinct identity of ancient Chinese cities. This is done by studying; feng shui notion, Yin and Yan forces, the theory of five elements and other Metaphysics philosophies of China. Furthermore, this paper scrutinises a number of Chinese ancient capital cities and temples of heaven in Beijing as case studies to measure to what extent the intangible factors contributed in shaping the identity and layout of Chinese cities and architecture.
\end{abstract}

Keyword: Traditional houses, vernacular architecture, magic square, five arts of Chinese, sustainable houses, feng shui art.

Date Received: $30^{\text {th }}$ April 2016

Date of Acceptance: $30^{\text {th }}$ October 2016 
Tamara Kelly

The Impact of Intangible Factors in Shaping the Identity of Ancient Cities and Architecture of China

\section{INTRODUCTION}

In order to understand the Chinese architecture, the culture of China must firstly be understood. Chinese believe in many metaphysics theories and one of these is the feng shui, which is one of the Five Arts of Chinese. It meant according to English dictionary wind-water. However the notion to Chinese is to harmonise the building and occupants with the surrounding environment or events within the universe. Traditionally, feng shui was widely used to orient buildings in certain direction to bring luck, for instance a providential building location should be determined by reference to local great features such as water body, a powerful stars, or a compass. Harley \& Woodward (2010) suggest that the better meaning of feng shui is the British one, which is positioning or placement than the word geomancy.

Therefore the application of this phrase led into siting the structures as buildings, villages, capital cities even a space within a building in favourable locations to benefit from the qi energy generated from nearby water body, mountains or other features of terrain. $Q i$ energy has a great influence on denizen mood and health of living occupant or even dead. "The Chinese art of siting has been applied in and mankind is its guardian a very wide range of spatial dimensions, from smallest of space- say bedroom or even the location of chair to largest, cosmic direction " (Harley \& Woodward, 2010, p.216).

Feng shui philosophy also articulates that qi energy exists in living creatures and inanimate objects or natural elements such as trees or hill. Moreover, $q i$ is created by two contradictory forces, Yin the female and Yan the male, and these two powers should be kept in balance neither the male dominating the female nor the opposite or else disaster and chaos will occur. These two forces come together to generate everything in our universe and represented by numbers, colours, seasons, direction, temperature, natural feature or other terms of endearment. For instance Yin (female) is even number, weak, earth or valley and refer to north direction and its colour is black or dark representing a poor, old and distraction status. The female force is winter, moon and water whereas the Yan (male) is white, heaven, odd numbers, light, sun, fire and the opposite of all female attributes. The male represents the south direction, rich, young, strong and summer season.

Yin and Yan interact together to create the five elements known as Wood, Metal, Water and fire, and consequently everything including living creatures and lifeless elements in our universe are made of these five components. In Chinese legends the tow forces male and female were born since the beginning of the cosmos establishment and their harmonized interaction took place at the centre of earth and has led to creation of the first human being and various deities. Hence centrality is a fundamental principle in Chinese architecture and it is evident through many case studies in this paper. For instance vital buildings such as emperor palaces or government buildings were commonly located at the core of 
PLANNING MALAYSIA

Journal of the Malaysia Institute of Planners (2017)

the city. According to this philosophy, humankind was in the centre of the universe and the link between earth and heaven. Furthermore, his duty is crucial to protect earth and maintain harmony among Yin and Yan and this notion led to establish the well field diagram. "The garden was the good Earth, and mankind is its guard for this he had to establish harmony in himself between yan and yin" (De Sheng, 1991, p.35).

\section{APPLICATION OF FENG-SHUI THEORY IN CITY PLANNING}

As mentioned earlier, feng shui principle articulates that building or city should have great link with surrounding milieu to benefit from $q i$ energy forthcoming from mountain or watercourses. Hence, most of ancient Chinese city were located at the mountain foot and nearby water body or forest. "Indigenous chicness religious traditions were based on a belief in life after death, ancestors worshiping and reverence for natural features such as trees, rocks and hills, as well as cosmic element such as sky, sun and moon" (Frenzo, Moffett \& Wodehouse, 2013, p.82). This approach underscores the link between architecture and the five element theory. For instance the forest provides the wood and fire whereas the mountain is source of earthy material needed for construction and act as barrier. Moreover, it assists in generating rain. Finally, the water body is for drinking, farming and fire control since wood is the main construction materials. "Mountains and rivers played an important role in the popular creeds of Chinese form the most remote antiquity they have been objects of worship. Mountains, forests, rivers, valleys, high hills have the power to produce rain, to make rain and wind: of all these things it is said that they are then a sacred powers" (De Sheng, 1991, p.31)

In fact, the influence of Yin and Yan theory is palpable in building orientation. Dwellings faces south to permit better air circulation, and maximize heat and light acquisition. Moreover, south represents Yan the male who is a symbol of richness youth and luck, and this resulted in grid layout of city to allow south positioning of premises. "The philosophy foundation of development of square-shaped cities in ancient china was determined by ancient philosophy such as the philosophy of YING-YANG along with the principle of the five elements of water, fire, earth, wood and metal. The theme of duality, which featured in these philosophy led to an emphasis on forming a central axis in the basic layout of cities in and also promoted symmetry" (Yanxin, 2010, p. 9).

In China the emperor duty expand beyond governing the nation. He is also in charge of choosing the best locations of his capital and other major cities to ensure good feng shui of new established cities. Therefore he sends his trusted officers to collect data concerning water availability and topographical aspects of the site, water quality should also be investigates as it effect farming and mankind health. "Feng shui is a philosophy with origins in the traditions of ancient Chinese Culture, which held great respect for man's natural environment and 
Tamara Kelly

The Impact of Intangible Factors in Shaping the Identity of Ancient Cities and Architecture of China

which had a significant impact on the choice of locations for the ancient cities and their layout" (Yanxin, 2010, p. 9).

The synthesis of qi energy with feng shui philosophy inspired the Chinese planners to invent the well field diagram or system which combined numbers, shapes and geomancy, the diagram acknowledge the setting of the emperor at the centre between heaven and earth by locating the palaces and governments buildings at the core of the diagram. The well field square comprises 9 squares numbered from 1 to 9 . The centre square is numbered by 5 representing the male power and featured the link with five elements which forms everything in the universe. Square 5 named the inner city accommodating royal palaces and other crucial buildings through which emperor governs the nation. Moreover, inner city is surrounded by wall and out of bound to the public. It is only for empower members, upper class citizens and government officers. Other odd numbers 1,3 and 7 accommodate multipurpose hall, temple of harvest and ancestor's temples and even numbers exist in the corner as female power to balance the male force accommodating residential villages or wards (Figure 1).



Figure 1 Well Field Square

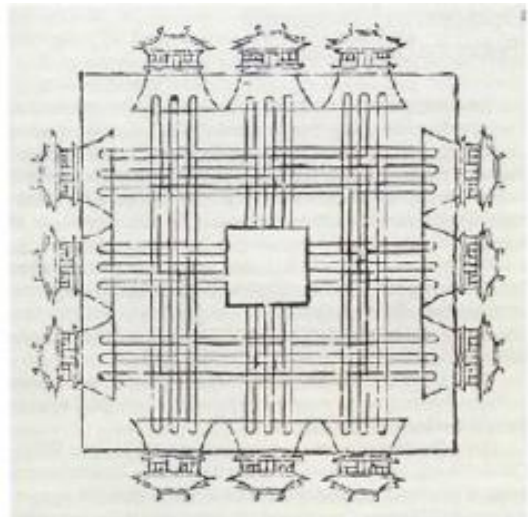

Figure 2 Zhou Dynasty Well field System

Another feature of the well field system is the nine main avenues running from North- South and West -East directions and they end in main gates on each opposite side. The entire city is protected by a second wall and the diagram layout was common during the Zhou Dynasty when the emperor power was dominating the religious authority. The first application of the diagram was adopted firstly in Chengzhou 1036 BC (Figure 2). "This plan, like its counterparts in several other Eurasian civilization, was designed to illustrate and establish the centrality of the ruler, the son of Heaven who sat at the pivot of the four quarters and meditate between heaven and earth. Hence emperor through Chinese history often concerned themselves with the geometric layout and numerological symbolism of 
PLANNING MALAYSIA

Journal of the Malaysia Institute of Planners (2017)

the capital and its cultic sites and structure." (Harley \& Woodward, 2010, p. 212). The layout of many other ancient cities in China such as Chang'an, Luoyang and Beijing were evidently inspired by the well field system. Usually, the emperor before establishing the well diagram on selected setting, would requested a report regarding the site to ensure it has a good feng shui and link with the five elements such mountain or natural terrain.

\section{CASE STUDY - CHANG'AN CITY}

Chang'an is primordial capital city for several dynasties in Chinese history was set up around 618AD (at present, the city referred to Xinjiang in Shaanxi). It was a great urban planning model and inspiration for many areas, and influenced the design of bordering nation Japan, in particular Kyoto and Nara cities. The Chang'an city was initiated in light of the well field diagram created during Zhou era and imparted basic components from Chengzhou city with the exception of internal city, the city roads were laid in matrix framework, and both inner and outer cities were fenced by walls. Entry to city is through odd gates. The royal premises or governments buildings occupying central square 5 were shifted northwards in Chang'an prototype to satisfy different traditions or notions (Figure $3)$.
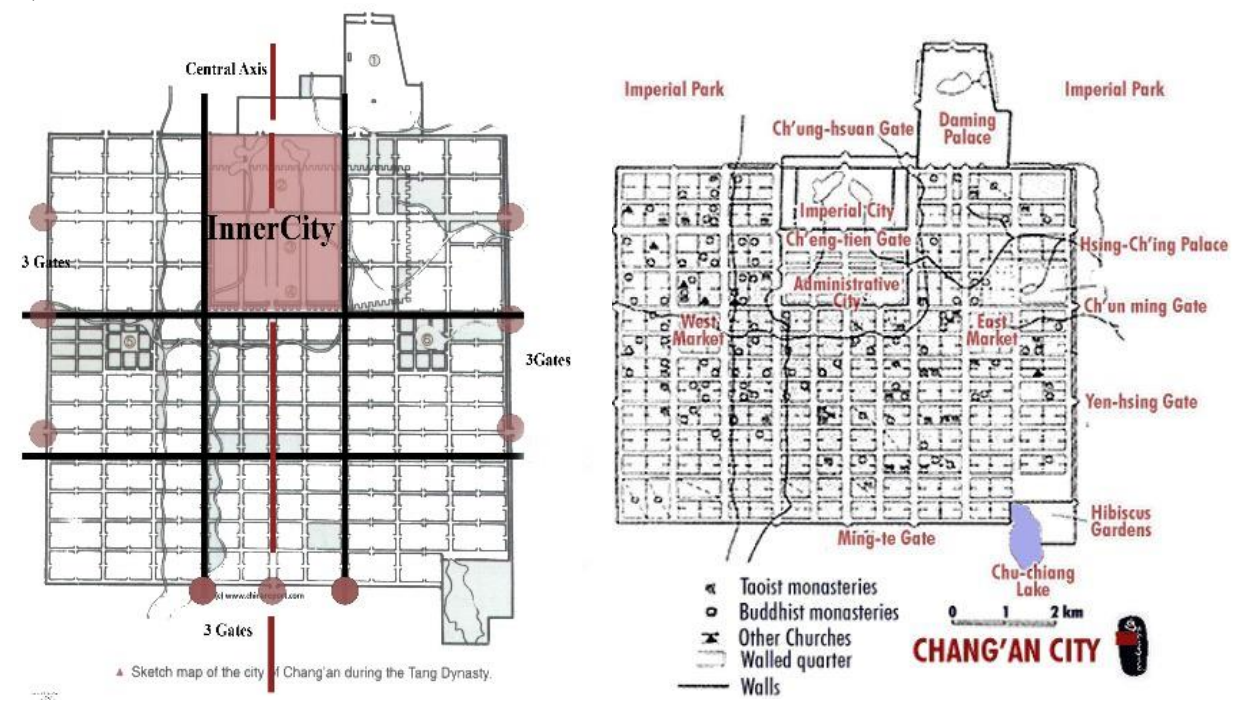

Figure 3 Chang'an Prototype

Many assumptions or reasoning behind such modification. Among those theories of the transference was to highlight the royal residence, as many orthogonal streets lead and end with limits of internal city. Further suggestion is to recognize the royal zone from external city or to diminish cuts in existing urban 
Tamara Kelly

The Impact of Intangible Factors in Shaping the Identity of Ancient Cities and Architecture of China

fabric. In fact, the rationale behind this adjustment was Qinling Mountain located north of the city acted as natural barrier and protected the inner city from possible conquest from north. Whereas the urban fabric beneath inner city is a further obstruction if invasion occur from southern direction. The city has good feng shui and connection with the five elements through the mountain and water source as Wei River with its streams flow through Chang'an city providing water supply for citizens.

\section{LUOYANG CITY}

Luoyang the timeworn city was situated on eastern China and in the west of Henan Province where Huanghe River (Yellow River) divided the city into two districts. The city is regarded as an antiquated capital of nine noteworthy lines in China. It was implicit the Zhou tradition as the eastern capital in acknowledgment of the effective foundation of Zhou. Initially the city was set up as capital thence advanced to be an incredible business hub. But the broadened part of the city was finished by Emperor Guangwu amid Han period. It is apparent that the city is comparable to previous case study (Chang'an) outline and its layout educed from the well field system. Yet the internal city is situated in the north of the scheme between two natural barricades, the mountain Mangshan in the north east embraces inner city and is a great barrier. Meanwhile, Luo River is southwards, segregating internal city form outer district (Figure 4).

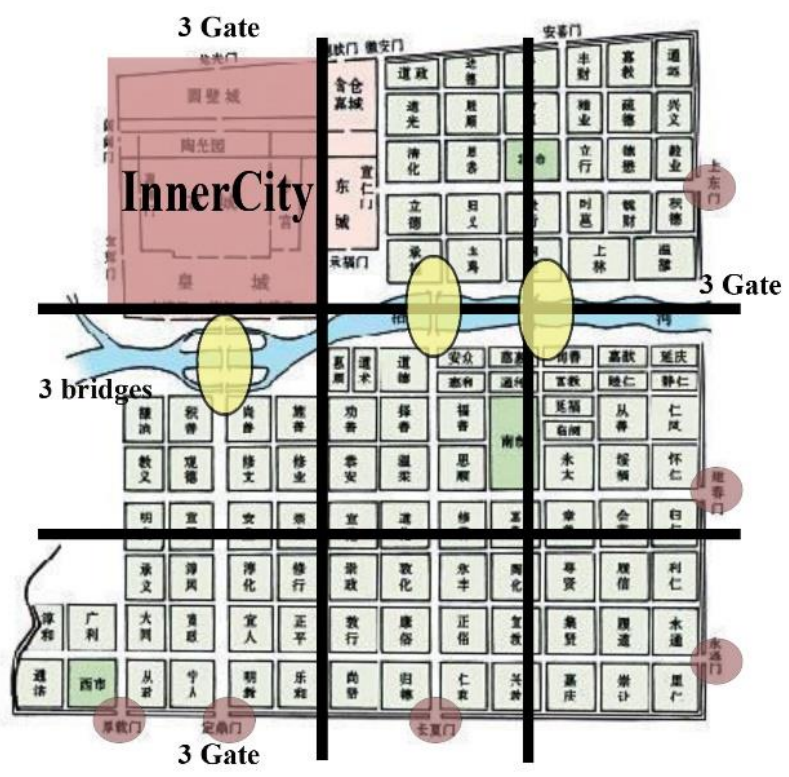

Figure 4 Luoyang the Timeworn City 
PLANNING MALAYSIA

Journal of the Malaysia Institute of Planners (2017)

The city is a squared grid layout once the river omitted and roads are orthogonal, similar to well field diagram. But the city irregular shape ensued by geological factor and the urban fabric east of the royal district is a third obstacle layer against invasion from east. The city has good feng shui through its location at the foot of the mountain and watercourse within its fabric. Furthermore, it acknowledges the male forces through the usage of odd digit 3 as the two banks of the city linked by 3 bridges and each side of external wall accommodates 3 main gates.

\section{BEIJING CITY}

Beijing, similar to Chang'an city, was an ancient capital of five lineages including the last three supreme dynasties (Zhou, Ming, and Qing). Likewise, it was the auxiliary principle of two northern administrations (Liao and Jin.). Beijing layout is considerably similar to the well field system in particular the location of inner city at core square number five with slight shift southwards to protect the city from conventional conquests attempts from Mongols state north of China. The design of the city and its components emulated the customary of urban arranging in old China. It highlighted the idea of central axis and a focal area of inward city to symbolize the stature of the supreme ruler who deemed as the focal point of the universe (Figure 5). "The imperial palace, known as inner or forbidden city, was built at the heart of Beijing bisecting the city symmetrically along a NorthSouth axis" (Yanxin, 2010, p. 17). Several treatments in the city reflect great recognition to feng shui philosophy and Yin -Yan forces through emphasizing southern orientation and main access to inner city likewise its premises is via south Axis. China was subject to frequent invasions from north when Mongolians cause severe destruction to many capitals. Hence, north is a symbol of annihilation, enemy, evil, poorness and bad luck. Central axis in Forbidden City (known as inner city) is stressed by locating crucial building along it and main route to agriculture as well as heaven temples is across same axis. Moreover, Meridian the main gate to inner city is on central path. Royal Buildings in Forbidden City were laid in group of three or five stressing the male force. Even the main gate Meridian accommodating three entry path and leads to five bridges over the stream (Figure 6). "The compound is divided into two complexes along the north-south axis; the southern outer court has three principles halls and the northern inner courtyard has another three main buildings" (Yanxin, 2010, $\mathrm{p}$. 3). Another feature of the Zhou diagram is to place sanctuaries on both sides of majestic palace. Hence the Ancestral temple was built to the left side of royal residence with Altar of earth on the right. Beijing city was changed over various densities, for instance the supreme city was moved southwards to enhance the entrance to the royal residence and another divider was developed outside the southern mass of the city during Ming dynasty. However, the wall was not finished on different sides because of absence of assets (Figure 6). "The southern 
Tamara Kelly

The Impact of Intangible Factors in Shaping the Identity of Ancient Cities and Architecture of China

wall of imperial city within Beijing city was relocated further southwards by approximately half mile, to facilitate the extension of the road (for imperia carriage) leading to the main gates of the innermost imperial palace" (Yanxin, 2010, p. 7).

The last modification of Beijing city occurred when the leader of the Ding line held the fundamental design of Beijing city and revamped the Palaces which were decimated by seismic tremor or blazed and requested to move neighbourhoods from the internal city into the external city while the inward city retained cabins and camps for the horde of the Imperial militaries.

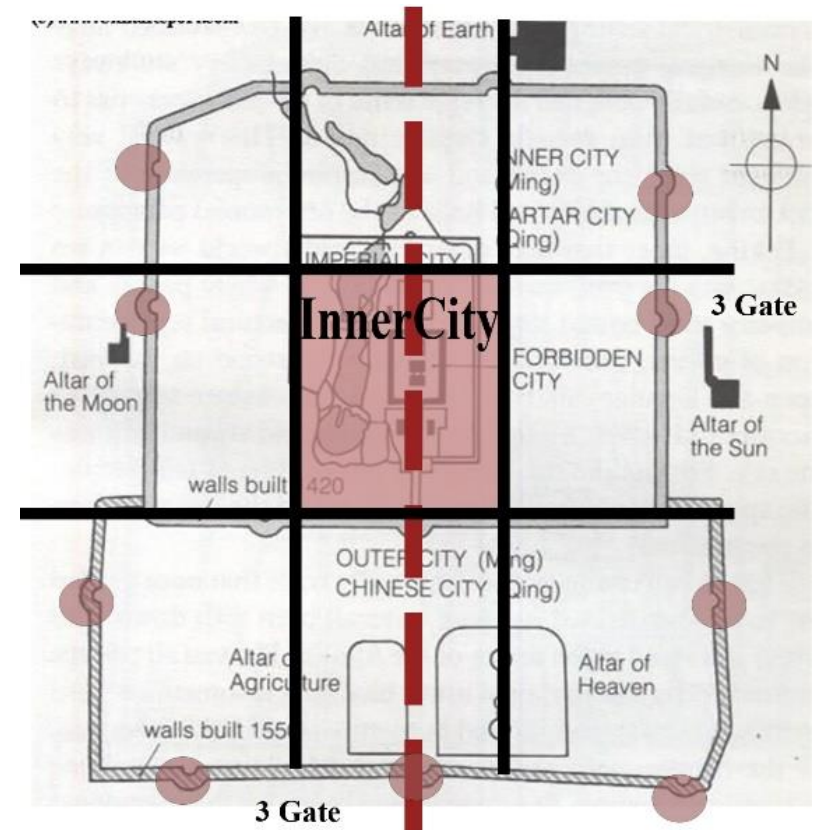

Figure 5 Beijing City Focal Point of the Universe

Like early antiquated urban areas specified, Beijing layout recognizes feng shui as the city shielded by various mountains and placed toward the end of Miaofeng Mountains and a few streams with aquatic canals spout through the city to supply drinking water to city populace. 
PLANNING MALAYSIA

Journal of the Malaysia Institute of Planners (2017)

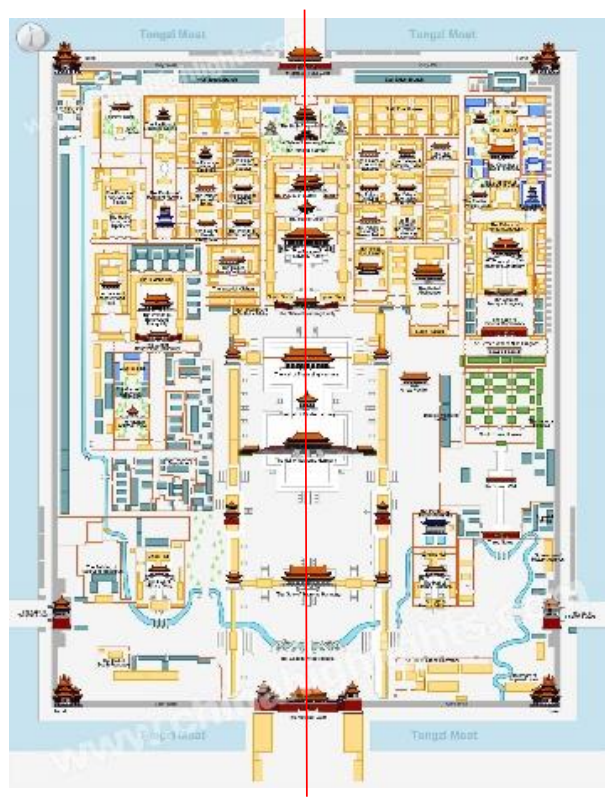

Figure 6 Main Gate Meridian

The legends and philosophies of Chinese cast its shadow on urban planning and even on buildings layout. For instance, temple of Heaven in Beijing emphasizing the Yan and Yin forces in particular the usage of number 3. The temple accommodates three components; the Hall of Prayer for Good Harvests, the Imperial Vault of Heaven and the Circular Mound Altar. Central Axis is dominant and entry into the temple and vital buildings were located along it. Main gateway to the halls accommodate three doors and access to temple is through southern direction. The Prayer hall crowned by thee roofing layer and stands on three rings of stones similar to Circular Mound Altar, stressing the male force (Figure 7).

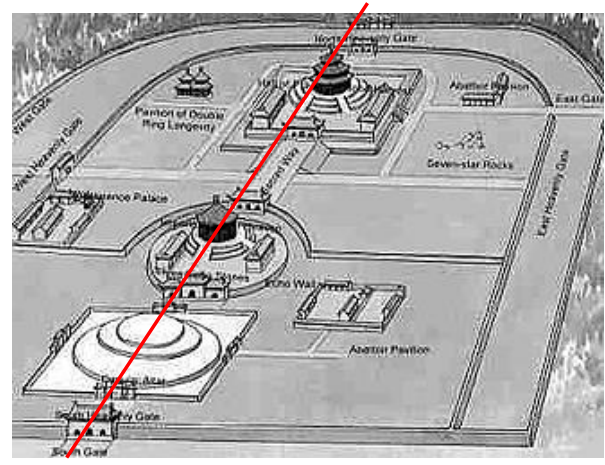

Figure 7 Circular Mound Altar 
Tamara Kelly

The Impact of Intangible Factors in Shaping the Identity of Ancient Cities and Architecture of China

\section{CONCLUSIONS}

The influence of Chinese mores and metaphysics theories is extremely evident in modelling the ancient cities of China and in particular feng shui philosophy and the two opposite forces Yin and Yan. Feng shui notion imposes great association with surrounding environment or even beyond our planet. It recognizes the stars and the entire cosmos. Feng shui principle and the theory of five elements were identified in the three case studies by establishing the cities at the foot of mountains and nearby water bodies to provide water for drinking and farming. Whereas, the mountains acted as natural barriers against possible invasions.

Another critical rationality in Chinese custom is pertinent to emperor stature and his position at the centre between earth and heaven. Emperor power overshadowed religious sovereignty during Zhou Dynasty. He was recognized as son of god and his duty was central to guard the earth and harmonizing the two main forces Yin and Yan. Hence ruler leverage was symbolized by focal area of magnificent castles or inward city inside the city arrangement, such as Beijing city. This vision inspired Chinese to develop the well field diagram during Zhou Dynasty and set it as guideline for many urban models where the administration premises and head royal residences involve the focal point of the outline or the city. The diagram addressed emperor perception and acknowledgment of order as great tool to rule the nation and organize society. Principal door to the city or royal residences normally situated along central access and dwellings commonly faces south direction. In effect, the guideline elements of pivotally and cardinal introduction are fundamental since Chinese trust that north spoke to the severities of winter, the danger of savage triumphs and malice impact while south speaks to paradise or positive Yang $q i$ subsequently. Essential structures opened towards southern heading and primary portability ways are south.

\section{REFERENCES}

De Sheng, A. L. (1991). Magic squares: the ancient Chinese city.

Yanxin, C. (2010). Chinese architecture. Cambridge: Cambridge University Press.

Barme. G. R. (2012). The Forbidden City. Harvard University Press.

Harley, J. B., \& Woodward, D. (2010). The history of cartography. Chicago: University of Chicago Press.

Frenzo, M., Moffett, M., \& Wodehouse, L. (2013). A world history of architecture. London: Laurence King Publisher. 